\title{
Videogames como conteúdo? Contribuições para uma proposta de ensino baseada na pedagogia dos multiletramentos
}

\begin{abstract}
Resumo
Este ensaio tem como objetivo sistematizar e socializar as contribuições para uma proposta de ensino de jogos digitais alicerçada na pedagogia dos multiletramentos. Trata-se de uma reflexão teórica que se baseia na bibliografia pertencente ao campo de investigação dos videogames. Como resultado, descrevem-se os processos de conhecimento e as atividades de aprendizagem com base na prática situada, na instrução explícita, no enquadramento crítico e na prática transformada. Por fim, evidencia-se a compatibilidade entre as orientações pedagógicas dos multiletramentos e os jogos digitais como domínio semiótico.
\end{abstract}

Palavras-chave: jogos digitais; multiletramentos; educação; design.

\section{Para citar este artigo:}

CRUZ JUNIOR, Gilson. Videogames como conteúdo? Contribuições para uma proposta de ensino baseada na pedagogia dos multiletramentos. Revista Linhas. Florianópolis, v. 22, n. 50, p. 320-350, set./dez. 2021. 


\title{
Video games as content? Contributions for an educational proposal based on the pedagogy of multiliteracies
}

\begin{abstract}
This essay aims to systematize and socialize contributions for an educational proposal for digital games founded on pedagogy of multiliteracies. This is a theoretical incursion that is supported by the literature pertaining to video game research field. As a result, it describes knowledge processes and learning activities based on situated practice, overt instruction, critical framework and transformed practice. Finally, it shows compatibility between the pedagogical guidance of multiliteracies and digital games as a semiotic domain.
\end{abstract}

Keywords: digital games; multiliteracies; education; design. 


\section{Introdução}

Desde a sua origem, os jogos digitais têm se afirmado como uma das principais forças culturais da atualidade. Presentes em plataformas diversas, como consoles, computadores e os cada vez mais generalizados smartphones, os games vêm forjando um amplo e variado acervo de experiências lúdicas, conquistando o interesse de públicos de todas as faixas etárias. Essa popularidade também se expressa em termos econômicos, manifestando-se na notória rentabilidade das indústrias de jogos cujas cifras movimentadas já superam vertentes tradicionais do entretenimento, como o cinema e a música.

Na medida em que se espalha por contextos variados, os jogos digitais têm se afastado definitivamente da condição de mero passatempo improdutivo. Graças ao reconhecimento de seu elevado potencial de engajamento e mobilização, os videogames se viram credenciados a cumprir um novo rol de papéis sociais, desde os mais simples e banais aos mais nobres e urgentes (MCGONIGAL, 2012). No contexto da saúde, um dos exemplos é a gameterapia, atividade na qual jogos eletrônicos são empregados em procedimentos clínicos e terapêuticos, auxiliando os processos de cura e reabilitação de pacientes portadores de debilidades físicas e/ou psíquicas.

Do mesmo modo, as potencialidades lúdicas dos jogos digitais também têm sido exploradas no âmbito da educação. Essa aproximação se baseia no entendimento de que a capacidade de atração intrínseca aos games representa uma das alternativas para reverter o estado de crise que há tempos assola as instituições educacionais. Acusadas de formar sujeitos passivos mediante concepções pedagógicas centradas na memorização mecânica de informações e em rígidas relações hierárquicas de poder e saber entre professores e alunos, escolas e estabelecimentos similares têm se tornado alvos frequentes de contestação. Em resposta a essas críticas, tais instituições têm se convertido em laboratórios e espaços de experimentação para abordagens pedagógicas classificadas como "inovadoras". Nesse contexto, os jogos digitais frequentemente despontam como recurso didático à disposição de docentes interessados em aliar conteúdos disciplinares com um fenômeno cultural de alta popularidade e adesão, sobretudo entre as novas gerações. 
Paralelamente, surgem perspectivas para as quais os games representam não apenas um "meio" a serviço da educação, mas também um "fim" para o qual esta deve se voltar. Para além do interesse em ferramentas e estratégias pedagógicas, essa abordagem destaca a legitimidade dos jogos como objetos de conhecimento, demonstrando como eles podem ser alvos de apreciação crítica, bem como núcleos de expressão criativa. Partindo desse entendimento, este ensaio se propõe a articular os jogos digitais com a pedagogia dos multiletramentos, esboçando elementos preliminares para uma proposta de ensino de games. Para isso, o texto se organiza conforme o seguinte roteiro de reflexão: 1) origem e caracterização da pedagogia dos multiletramentos; 2) os jogos digitais como domínio expressivo; e 3) contribuições para uma proposta de ensino de jogos digitais a partir dos multiletramentos.

\section{A pedagogia dos multiletramentos}

A origem da noção de multiletramento é constantemente associada aos esforços do New London Group (NLG): grupo de pesquisadores que, em 1996, se reuniu na cidade de Nova Londres, Estados Unidos, com a finalidade de discutir o futuro da alfabetização na virada do século 21. O resultado desse encontro foi sistematizado na forma de um manifesto que delineou a noção de "pedagogia dos multiletramentos", sendo assinado por vários especialistas da área da linguística, como Bill Cope, Mary Kalantzis, Gunther Kress, Norman Fairclough e James Paul Gee. Nos anos que se seguiram, o NLG se sensibilizou em relação à importância crescente das tecnologias da informação e comunicação nas práticas cotidianas e educacionais. Em 2009, dois de seus integrantes, Bill Cope e Mary Kalantizis, publicaram um conjunto de ensaios nos quais revisitam ideias do manifesto original, atualizando-o e associando suas ideias às novas linguagens popularizadas pelas mídias digitais (COPE; KALANTZIS, 2009a; 2009b; 2009c).

Em termos de organização, Cope e Kalantzis (2009b) estruturam sua proposta partindo das indagações sobre o "porquê", o "quê" e o "como" da pedagogia dos multiletramentos. No que diz respeito à primeira (o porquê), os autores apontam um conjunto de transformações ocorridas no plano dos processos de representação e produção de significados, entre as quais, destacam a afirmação do caráter multilinguístico 
e multimodal da alfabetização. Trata-se de uma ocorrência intimamente ligada ao alargamento do entendimento acadêmico sobre "leitura" e "escrita". Em linhas gerais, esse movimento tem ajudado a colocar em xeque o monopólio da linguagem verbal/fonética em relação a outras formas de expressão, estimulando o estudo e o ensino de novas e antigas práticas comunicacionais no âmbito dos projetos de letramento.

"O porquê" da pedagogia dos multiletramentos também inscreve a proposta em concepções ampliadas de formação. Nessa perspectiva, a educação é definida como meio responsável por garantir o acesso das pessoas aos recursos capazes de fornecer: a) melhores oportunidades de emprego e inserções profissionais; b) competências essenciais ao exercício efetivo da cidadania e da participação sociopolítica; e c) saberes e fazeres que contribuam para o desenvolvimento pessoal. Acima de tudo, essa visão reforça o papel da educação como componente-chave na promoção de equidade e justiça social. De fato, não são raras as críticas ao desempenho insuficiente da educação institucional no cumprimento desse tipo de meta, sobretudo no tocante à redução de desigualdades de classe: “o fosso entre ricos e pobres está crescendo, e mesmo quando os pobres às vezes se tornam um pouco menos pobres, raramente isso ocorre porque a educação melhorou" (COPE; KALANTZIS, 2009b, p. 168). Não obstante, com o respaldo de macrotransformações induzidas pela chamada "economia do conhecimento", a educação formal permanece no posto de protagonista da formação de indivíduos, trabalhadores e cidadãos preparados para enfrentar os desafios do século 21 - ainda que não isenta de percalços.

Em outro viés, o "o quê" dos multiletramentos esboça os contornos de uma pedagogia da multimodalidade. Esta proposta apresenta diferenças marcantes em relação às abordagens tradicionais da alfabetização, principalmente no que diz respeito ao seu entendimento sobre os processos de produção de sentido (a semiose). Nos modelos clássicos, os aprendizes são considerados receptores passivos ou, na melhor das hipóteses, "agentes de reprodução de formas representacionais recebidas, sancionadas e oficiais" (COPE; KALANTZIS, 2009b, p. 175, tradução nossa). Sob outra perspectiva, a multimodalidade desafia o primado da linguagem verbal, favorecendo a (re)descoberta de domínios semióticos até então marginalizados pela educação formal, como aqueles 
encarnados nas linguagens visual, tátil, gestual e espacial. Essa visão, explicam Cope e Kalantzis (2009b), está menos preocupada com as tecnicidades ensináveis dos sistemas de significados, deslocando seu foco para a "heurística dos aprendizes", isto é, ao conjunto de ações educativas que estimulam os educandos a se engajarem ativamente num campo enormemente variado e plural de textos.

Vale ressaltar que a valorização de visões ampliadas acerca da linguagem e da alfabetização é uma reivindicação emergente no campo da educação (COSCARELLI; KERSCH, 2016; DUDENEY; HOCKLY; PEGRUM, 2016; ROJO, 2013). Sobre isso, MartinBarbero (2014) ressalta o quanto esse movimento é essencial para a superação daquilo que ele chama de razão dualista na relação entre livros e (novos) meios de comunicação. Historicamente, os primeiros têm sido encarados como emblemas do conhecimento, da erudição e do esclarecimento, enquanto os últimos permanecem sob o estigma da suspeita, da manipulação, da alienação e do fascínio acéfalo que desvirtua as massas. Para o autor, trata-se de um raciocínio dicotômico, metafísico e pessimista que transforma em bode expiatório inúmeras formas expressivas e midiáticas em ascensão, responsabilizando-as pela suposta degradação cultural e pelo vazio moral do mundo contemporâneo. Rejeitando esse diagnóstico, destaca a importância de um tom conciliatório que resgate o dinamismo do conhecimento distribuído entre múltiplos suportes, práticas comunicacionais e modos de socialização:

O livro continuará sendo peça-chave na medida em que a primeira alfabetização, a que abre o mundo da escritura fonética, em lugar de fechar-se sobre a cultura letrada, lance as bases para a segunda alfabetização, aquela que nos abre às múltiplas escrituras que hoje conformam o mundo do audiovisual e do texto eletrônico. A mudança nos protocolos e processos de leitura (SARLO, 1998) que, sem dúvida, atravessamos não significa, não pode nem deve significar, a substituição de um modo de ler por outro, mas sim a complexa articulação de uns e outros, da recíproca inserção de uns em outros, entre livros, quadrinhos, vídeos e hipertextos. Com tudo o que isso implica de continuidades e rupturas entre os muitos canônicos modos de ler livros e os muitos anárquicos modos de navegar textos. De um mínimo de continuidade e conversação entre eles vai depender em boa medida não só o futuro da civilização ocidental, mas o sentido social da vida e o porvir da democracia, que são as exigências feitas à educação para que seja capaz de formar cidadãos que saibam ler tanto jornais impressos como televisivos, videogames, videoclipes e hipertextos. (MARTIN-BARBERO, 2014, p. 51-52) 
Outro fundamento da pedagogia dos multiletramentos é a sua aliança com o campo do design. Em sentido amplo, o termo "design" remete tanto a um ato de criação/construção quanto à estrutura e morfologia intrínsecas daquilo que é construído. Cope e Kalantzis (2009b) esclarecem que essa perspectiva favorece uma visão mais dinâmica dos processos de representação, afastando-os de visões conservadoras centradas unicamente no ensino da gramática e dos cânones literários. Na condição de atividade de criação, o design consiste no processo de representação de significados, seja de um indivíduo para si mesmo, como nas situações que envolvem os atos de ler, escutar ou ver, seja de um indivíduo para terceiros, a exemplo de situações de escrita, fala e criação de imagens. Para isso, a pedagogia dos multiletramentos se concentra em três dimensões-chave das atividades do design:

1) Designs disponíveis - o contato com recursos à disposição da produção de significado e que normalmente se manifestam na forma de culturas, contextos, padrões e convenções que modelam diferentes sistemas formais de signos;

2) Desenhando ${ }^{1}$ - o trabalho realizado com/sobre os designs disponíveis para representar o mundo para si e/ou para outros;

3) O redesenhado - o mundo transformado por intermédio da criação de novos designs disponíveis e/ou da mudança do próprio agente produtor de significados por meio do ato criativo.

A pedagogia dos multiletramentos reconhece o papel central da agência social e individual na produção de significados, buscando, assim, estabelecer um modelo educacional com maior abertura à criatividade, à inovação e ao empoderamento dos aprendizes. Como consequência, o ensino deixa de operar unicamente em função do desenvolvimento de competências técnicas, investindo igualmente na formação de um tipo específico de pessoa: um produtor ativo de significados multimodais.

Por fim, o "como" dos multiletramentos reforça o espírito transformador da proposta, prescrevendo um conjunto de orientações pedagógicas gerais. Nesse sentido, as intervenções formativas alinhadas a essa perspectiva operam em função de quatro macrodimensões educativas distintas: 1) a prática situada; 2) a instrução explícita; 3) o

\footnotetext{
${ }^{1} \mathrm{Na}$ língua inglesa, a expressão design cumpre tanto o papel substantivo quanto verbal. No primeiro caso, a palavra será utilizada sem alterações. Já no segundo, será traduzida na forma do verbo “desenhar”.
} 
enquadramento crítico; e 4) a prática transformada. Por sua vez, cada uma delas se materializa em ações didáticas sustentadas por processos de conhecimento específicos, os quais podem ser traduzidos verbalmente pelos atos de experienciar, conceitualizar, analisar e aplicar.

A prática situada subentende que a cognição humana é sempre contextual e que os significados estão enraizados no mundo real, mais especificamente, em práticas socioculturais. Nesse eixo, as ações de aprendizagem buscam promover a imersão do educando num dado universo linguístico mediante estratégias como: a) experienciar o familiar - a realização de atividades nas quais os educandos identificam e refletem sobre suas vivências, seus conhecimentos e seus interesses em relação à(s) modalidade(s) de texto em foco; e b) experienciar o novo - situações em que educandos são convidados a interagir com modalidades textuais distantes ou inexistentes em seu cotidiano, no intuito de alimentar sua base de conhecimento e ampliar seu repertório de "experiências familiares".

Já a instrução explícita é a fase em que ocorrem os estímulos à compreensão ampliada dos textos por intermédio do contato com conhecimentos especializados. Para isso, essa abordagem se afasta do modelo professoral clássico, colocando em seu lugar todas as estratégias que estimulam os educandos a constituir uma relação questionadora e investigativa com as teorias e os conceitos estudados. Nessa vertente, os processos de aprendizagem se efetivam nos atos de: a) conceituar nomeando - introduzir termos, palavras e denominações que ajudem o educando a identificar diferenças e semelhanças entre textos de uma mesma modalidade, classificando-os e categorizando-os de acordo com suas propriedades semióticas; e b) conceituar teorizando - apresentar sistemas explicativos e interpretativos científicos e/ou disciplinares por meio dos quais os educandos possam articular conceitos e formular seus próprios modelos mentais.

Por sua vez, o enquadramento crítico atua no desenvolvimento de habilidades de julgamento e avaliação. Para tanto, sustenta-se em atividades envolvendo: a) análise funcional - o estabelecimento de relações de causa e efeito entre diferentes elementos formais, juntamente com a formulação de linhas de raciocínio e deduções acerca da estrutura formal dos textos; e b) análise crítica - o confronto com as dimensões 
ideológica e discursiva dos textos, aliado à identificação e ao questionamento dos interesses implícitos nos significados por eles difundidos.

Aqui convém reforçar a natureza intercambiável das macrodimensões didáticas da pedagogia dos multiletramentos. Esse traço permite, por exemplo, que as vivências realizadas no âmbito do enquadramento crítico sejam enriquecidas por atividades realizadas nas demais fases da proposta. Ou seja, a análise funcional e crítica de textos são exercícios potencializados tanto pelo contato com experiências novas e familiares (a prática situada), quanto pela posse e mobilização de conceitos e teorias especializadas (a instrução explícita).

Finalmente, a prática transformada desafia os educandos a colocarem em ação, em situações "práticas", as habilidades, as experiências e os conhecimentos construídos até então. Para isso, apoia-se nas seguintes ações de aprendizagem: a) aplicação apropriada - ocorre em circunstâncias que devem reproduzir, de modo previsível e controlado, a complexidade do mundo real, permitindo que os educandos testem e validem sua proficiência na produção de significados específicos; e b) aplicação criativa promove o exercício espontâneo da imaginação, de modo que os educandos tenham condições de expressar livremente seus próprios interesses, desejos e visões de mundo, abrindo caminhos para a emergência de textos e formas textuais inteira ou parcialmente originais.

Em linhas gerais, as ações de aprendizagem relativas ao "como" dos multiletramentos podem ser descritas da seguinte maneira (Quadro 1):

Quadro 1-O “como" dos multiletramentos

\begin{tabular}{|l|l|}
\hline \multicolumn{2}{|c|}{ O “como" dos multiletramentos: as microdinâmicas da pedagogia } \\
\hline Orientações pedagógicas & Processos de conhecimento \\
\hline Prática situada & $\begin{array}{l}\text { Experienciar } \\
\text {... o Familiar } \\
\text {... o Novo }\end{array}$ \\
\hline Instrução explícita & $\begin{array}{l}\text { Conceitualizar } \\
\text {... Nomeando } \\
\text {... Teorizando }\end{array}$ \\
\hline Enquadramento crítico & $\begin{array}{l}\text { Analisar } \\
\text {... Funcionalmente } \\
\text {... Criticamente }\end{array}$ \\
\hline Prática transformada & $\begin{array}{l}\text { Aplicar } \\
\text {... Apropriadamente } \\
\text {... Criativamente }\end{array}$ \\
\hline
\end{tabular}

Fonte: Cope e Kalantzis (2009). 
De modo geral, a perspectiva dos multiletramentos demonstra uma compreensão ampliada dos processos de representação, extrapolando os limites impostos pela alfabetização tradicional e sua fixação pela linguagem verbal. Em contraste com esse modelo, define-se como uma pedagogia do design e da multimodalidade. Enquanto a primeira ideia serve de quadro de referência que estimula a proatividade e a inovação nas relações entre educandos e textos, a segunda oportuniza a abertura do letramento ao caráter multilinguístico e multicultural dos significados. Sendo assim, de que modo a pedagogia dos multiletramentos pode auxiliar na construção de uma proposta de ensino concernida nos jogos digitais? Antes de evidenciar essa articulação, é conveniente tecer considerações, ainda que breves, sobre os games como linguagem.

\section{Jogos digitais como forma expressiva}

Do ponto de vista cultural, os jogos digitais representam um fenômeno complexo e, como tal, dotado de múltiplas possibilidades de descrição. No âmbito das ciências humanas, uma das principais estratégias para o estudo do tema são as teorias clássicas do jogo. Esse diálogo parte do pressuposto de que os games correspondem a um conjunto de variantes tecnologicamente mediadas das manifestações lúdicas pré-digitais. Ou seja, subentende que os jogos digitais representam uma espécie de descendente direto dos jogos tradicionais.

Apesar de suas limitações², essa abordagem permanece popular, proporcionando contribuições relevantes ao debate, entre as quais se destaca o "modelo clássico de jogo". Formulado por Jesper Juul (2019), esse esquema reúne um conjunto de atributos fundamentais presentes em todos os tipos de jogo. Trata-se de um produto resultante de esforços de síntese e análise da literatura especializada, abrangendo autores como Johann Huizinga, Roger Caillois, Bernard Suits, Brian Sutton-Smith e Chris Crawford.

\footnotetext{
${ }^{2}$ No âmbito das ciências humanas, é comum que as teorizações dos jogos digitais se sustentem no pressuposto de que os games correspondem a um desdobramento natural dos jogos tradicionais que, por sua vez, compõem um campo de investigação do qual são extraídos autores e estudiosos que tendem a ser considerados como a base indispensável para compreender os videogames. Apesar de plausível, esse raciocínio tem restringido as possibilidades de abordar os jogos digitais como materialidade, isto é, como fenômeno multifacetado, interdisciplinar e, portanto, prenhe em termos de modelos de descrição e análise. Além de uma atividade lúdica, os videogames podem, por exemplo, ser enquadrados como um conjunto de códigos programados em sistemas computacionais, olhar que os reinscreveria no âmbito de disciplinas e áreas do conhecimento fora das humanidades (CRUZ JUNIOR, 2017).
} 
Como resultado, o modelo elenca um total de seis características comuns entre jogos digitais e jogos tradicionais, além de estabelecer uma base de compreensão que resume o jogo como sistema formal, isto é, como um fenômeno abstrato dissociado da experiência subjetiva dos jogadores. Esses atributos são:

1) Regras: jogos são atividades inerentemente orientadas por normas e restrições;

2) Resultado quantificável e variável: o desfecho de um jogo deve ser imprevisível, além de objetivamente identificável por todos os seus participantes;

3) Valorização do resultado: os diferentes desfechos possíveis de um jogo estão sujeitos à classificação e à hierarquização entre "bons" e "maus" resultados;

4) Esforço do jogador: os participantes do jogo devem se empenhar para interferir no resultado do jogo;

5) Jogador ligado ao resultado: além do vínculo emocional expresso pelo desejo de obter o prazer de um bom resultado, o desfecho do jogo deve discriminar o desempenho individual de cada jogador ou equipe, permitindo, por exemplo, distinguir "vencedores" e "perdedores";

6) Consequências negociáveis: jogos podem ser jogados com ou sem consequências para a vida cotidiana.

No cerne das relações entre jogo e jogador residem as principais operações comunicacionais dos games. O significado é um elemento inseparável do gameplay, ideia aqui entendida como a experiência resultante da interação entre jogador e jogo. Em geral, o jogo representa uma circunstância que interrompe o funcionamento habitual da vida cotidiana, revestindo temporariamente objetos, pessoas e comportamentos com novos sentidos, instaurando temporariamente um "círculo mágico" sustentado num regime semântico particular: é o momento em que crianças se transformam em heróis, pedaços de madeira em espadas e marcações de giz em campo de batalha. Essa transfiguração ocorre tanto em jogos digitais quanto nos jogos tradicionais. Estes diferem apenas no modo como o contexto de jogo é retratado: enquanto os últimos contam unicamente com o apoio da imaginação de quem joga, os primeiros dispõem de um amplo arsenal de estímulos audiovisuais, hardwares e interfaces de comando. 
A importância da representação é igualmente presente no âmbito do design de jogos. Para Salen e Zimmerman (2012), os game designers são especialistas em criar experiências de jogo capazes de proporcionar a interação lúdica significativa (meaningful play). $O$ jogo é uma atividade que exige a realização de escolhas no interior de um sistema complexo projetado para possibilitar certos comportamentos e impedir outros. Ao executar uma ação, o jogador produz significados específicos no interior do sistema lúdico, imprimindo em seu ato a expressão de uma leitura estratégica de jogo: "Por exemplo, depois de mover uma peça no xadrez, as relações recém-estabelecidas entre as peças [...] dão origem a um novo significado - significados criados pela ação do jogador" (p. 49). Sob essa ótica, a interação lúdica significativa assume duas funções distintas: a) descritiva, referindo-se à tarefa de especificar o modo como cada ação do jogador interfere no andamento e desfecho do jogo; e b) avaliativa, atuando como referência para classificar o grau de eficiência com o qual um game e seus significados conseguem se comunicar adequadamente com o jogador.

A interação lúdica significativa destaca a dinâmica de retroalimentação entre as ações do jogador e os feedbacks dados a ele pelo jogo. Para resultar em experiências de diversão e engajamento, esse ciclo deve se basear num modelo de comunicação eficaz entre humano e máquina - ou regras, no caso dos jogos tradicionais. Para isso, os significados produzidos e materializados pelo sistema do jogo devem ser percebidos pelo jogador de formas necessariamente:

- Discerníveis: no momento em que executa uma ação, o jogador deve ser capaz de perceber as mudanças no estado do game, caso contrário não conseguirá fazer uma leitura de jogo confiável e, por consequência, terá dificuldades em formular estratégias, tornando seus esforços sem sentido. Em Super Mario World (1990), o jogador sempre ouve um sinal sonoro ao coletar moedas cuja soma total é exibida em tempo real na parte superior da tela. Ou ainda, como nos games de RPG, em que cada inimigo derrotado ou missão cumprida rende ao jogador pontos de experiência, dinheiro e espólios detalhados em barras de status;

- Integrados: o resultado de uma ação deve estar em consonância com todos os sistemas de regras presentes no jogo, de modo que o jogador perceba cada 
escolha tomada por ele como uma "parte" articulada a um "todo" maior e complexo composto pelo gameplay. Ao acumular 100 moedas, Mario é sempre premiado com uma vida que, por sua vez, deixa o jogador mais longe de um temido game over. Já nos RPGs, os pontos de experiência acumulados permitem ao jogador subir de nível, e com isso adquirir novas habilidades, melhorando seu desempenho nas missões, além de credenciá-lo a realizar tarefas de maior dificuldade.

O diálogo com o game design ajuda a realçar a afinidade dos jogos digitais com a pedagogia dos multiletramentos ${ }^{3}$. Ao serem entendidos como sistemas de representação nos quais o jogador "lê" e "escreve" simultaneamente a partir do gameplay, é permitido afirmar que os games correspondem a uma modalidade textual singular, estando, portanto, abertos ao diálogo com categorias-chave do campo da linguística. Mais do que isso, são textos multimodais por excelência, combinando linguagens audiovisuais, textuais e espaciais, assim como suas respectivas matrizes semânticas. Os games também estão submetidos às convenções de gênero, de modo que cada experiência de jogo reproduz, em maior ou menor medida, estruturas formais preestabelecidas por jogos anteriores, podendo tanto reproduzir categorias típicas em outras modalidades textuais (ação, aventura, terror), quanto constituir gêneros próprios (tiro em primeira pessoa, RPG, corrida, survival horror, roguelike, tower defense). Por fim, ao combinarem sistemas de regras com elementos ficcionais e narrativos, os jogos também realçam sua função discursiva e sua capacidade de enunciar visões de mundo variadas sobre os temas que aborda e as experiências que proporciona ao jogador.

\section{Jogos e multiletramentos: elementos para uma proposta de ensino}

Nesta seção serão apresentadas algumas possibilidades de articulação entre o "como" da pedagogia dos multiletramentos e a linguagem dos jogos digitais. Para isso, recorro ao diálogo com a bibliografia especializada do campo de conhecimento dos videogames, no intuito de reunir subsídios teóricos e metodológicos capazes de inspirar

\footnotetext{
3 Para mais detalhes sobre as relações entre jogos digitais e a noção de letramento, recomendo o trabalho de revisão: ALBUQUERQUE, Rafael Marques. O letramento eletrolúdico como conscientização: bases teóricas para educar o jogar. Currículo sem fronteiras, Porto Alegre, v. 14, n. 2, p. 57-74, 2014.
} 
práticas educativas concretas. Em termos de organização, esse modelo será descrito em conformidade com as quatro macrodimensões pedagógicas esboçadas anteriormente (prática situada, instrução aberta, enquadramento crítico e prática transformada). Vale ressaltar que estas não correspondem a etapas rígidas no interior de um esquema didático fechado e linear. Ainda que entre cada uma delas existam relações de interdependência e complementaridade, essas linhas de ação podem ser implementadas de modo flexível, respeitando as particularidades de cada contexto e projeto pedagógico.

No âmbito da prática situada, como vimos, os processos de conhecimento estão subordinados ao ato de experienciar. Transposta para o território dos games, essa ação imediatamente remete à centralidade do jogar como modo primário de acessar o conteúdo dos jogos. Todavia, o gameplay não é uma atividade uniforme e homogênea, já que existem diferentes maneiras de jogar um mesmo jogo. Um exemplo vem dos e-sports (esportes eletrônicos), universo em que os jogadores se transformam em "atletas" que, afastando-se da lógica do divertimento desinteressado, interagem com os games a partir de uma disposição metacompetitiva ${ }^{4}$ voltada ao alto rendimento (TAYLOR, 2012). Outro exemplo são as speedruns: performances extremas em que jogos são finalizados em tempo recorde e cujas gravações costumam ser compartilhadas na internet a fim de dar transparência ao feito e garantir a sua validação perante a comunidade de jogadores. Também existem as partidas sem mortes (no death) e sem danos (no damage), cuja finalidade é zerar um jogo sem morrer ou sem ser atingido por nenhum inimigo, respectivamente. Fenômenos como as speedruns e os e-sports demonstram como o gameplay, para além de satisfazer/divertir o próprio jogador, pode adquirir conotações variadas, por exemplo, transformando-se num acontecimento espetacular que atrai a atenção de um grande público. Existem ainda formas de jogo que podem estimular a subversão da lógica intrínseca a um título ou gênero, como é o caso do "modo pacifista", no qual jogadores são desafiados a zerar games usualmente rotulados de "violentos", como Fallout e Grand Theft Auto, sem matar qualquer personagem.

O modo como um game é jogado não altera o jogo como sistema formal, apenas interfere na maneira como o jogador o percebe e com ele se relaciona. Como afirma

\footnotetext{
${ }^{4}$ Muitos games envolvem batalhas entre jogadores. Entretanto, a metacompetição remete à assimilação dos confrontos que ocorrem dentro jogo em competições e torneios oficiais fora do jogo, como é o caso dos campeonatos promovidos por e-sports.
} 
Newman (2008, p. 16), a experiência de jogo representa uma performance configurativa em que "[...] é a plasticidade do modelo de simulação e sua mutabilidade inerente que facilita a modificação e transformação através de padrões inovadores e inventivos de desempenho e jogo." O autor também explica que tão variáveis quanto os modos de jogar um mesmo jogo são as maneiras como um mesmo jogador joga com o passar do tempo. O gameplay é uma experiência influenciada por circunstâncias sociais, técnicas e subjetivas. Logo, a atividade do jogador é afetada por fatores diversificados que vão desde a estrutura de interação oferecida pelo jogo em si, até a sociabilidade estabelecida pelo player com outros jogadores e sua cultura.

Em termos educacionais, uma das funções do ato de experienciar os videogames, jogando-os, é obter acesso à bagagem cultural dos educandos e com isso abrir caminhos para expandi-la. De um lado, ao serem instigados a vivenciar o familiar, os jogadores estarão oferecendo informações sobre o seu repertório de conhecimentos em relação aos games, aos gêneros, às plataformas e aos estilos de jogo mais presentes em seu cotidiano. Do outro, experienciar o "novo" implica uma intervenção concreta do educador no sentido de ofertar oportunidades que possam expandir o mosaico de vivências do(s) educando(s), partindo das lacunas identificadas nas situações de imersão no "familiar". Evidentemente, os dois tipos de prática (novas e familiares) são interdependentes, na medida em que a definição do que é "novo" depende daquilo que se manifesta como familiar em cada cenário (grupo ou turma): se os educandos somente consomem jogos casuais ${ }^{5}$ em telefones celulares e/ou dispositivos móveis, o ineditismo pode vir de proposições que abarquem games hardcore exclusivos de consoles e demais plataformas especializadas. O "novo" também pode resultar do contato com novos padrões de jogo, ou seja, novas maneiras de jogar os jogos com quais já se está familiarizado. Tais esforços devem permitir que o jogador-educando desenvolva um repertório mais rico e heterogêneo de experiências de jogo, expandindo seu entendimento a partir de interações variadas com o universo dos games.

\footnotetext{
5 Diferente dos jogos hardcore que costumam exigir do jogador um alto investimento de tempo, aprendizado e, por vezes, dinheiro, os games casuais foram criados para um público mais abrangente, que não se enquadra na imagem estereotípica do gamer. Geralmente, os títulos nesse nicho são projetados para serem jogados em sessões curtas, terem uma curva de aprendizado amigável e poderem ser adquiridos gratuitamente (JUUL, 2010).
} 
Nesse processo, é igualmente necessário observar o (provável) surgimento de disparidades entre os indivíduos que "jogam" e os que "não jogam" videogames. Diferentemente da leitura dos textos que acessamos por via da alfabetização tradicional, o contato com os textos dos jogos digitais não costuma ser ampla e precocemente estimulado, sobretudo em espaços e tempos educacionais. Por essa razão, propostas pedagógicas com anseios emancipatórios devem antever os descompassos entre aqueles indivíduos para quem os videogames são uma atividade cotidiana e aqueles para quem o jogar representa uma ocasião de descoberta, de aprendizagem e, provavelmente, de percalços. Como alternativa para minimizar esse desequilíbrio, Ulicsak e Williamson (2010) sugerem que os educandos com maior know-how sejam incentivados a oferecer suporte aos colegas iniciantes que enfrentam dificuldades. Trata-se de uma tática muito oportuna à concepção de sujeito preconizada pela pedagogia dos multiletramentos, que valoriza o desenvolvimento de atributos como iniciativa, trabalho em equipe e abertura ao diálogo.

Já na instrução explícita, os educandos são estimulados a abstrair as atividades de jogo. Trata-se de dar concretude e profundidade aos saberes latentes no gameplay, transformando saberes tácitos - inconscientes e invisíveis - em explícitos. Mais especificamente, é o momento em que o jogador acessa e constrói conhecimentos que ampliam sua consciência em relação aos fatores que determinam a natureza e os significados em cada game. $\mathrm{O}$ ato de conceitualizar jogos envolve a apropriação, a mobilização e a (re)formulação de ideias e operadores lógicos que ajudam o educando a estabelecer relações de distinção e semelhança entre jogos, para que assim seja possível classificá-los de acordo com tipologias e critérios distintos.

Não há um método único e universal que contenha todos os conceitos necessários para nomear e teorizar cada um dos elementos presentes nos textos dos jogos digitais. A dificuldade de estabelecer um marco referencial dessa natureza se deve, em parte, ao crescente número de disciplinas acadêmicas produzindo conhecimentos sobre 0 fenômeno dos games, dentre as quais se destacam a Computação, a Comunicação, os Estudos Literários, a Linguística, a História, a Psicologia e as Ciências da Educação.

Ainda assim, diante da necessidade de definir um ponto de partida, o campo do game design novamente se apresenta como uma opção oportuna. Nele se originou uma das ideias mais relevantes para o estudo dos jogos digitais na atualidade: a mecânica. 
Trata-se do termo empregado para nomear as unidades estruturais primárias de um jogo (BRATHWAITHE; SCHREIBER, 2009; HUNICKE; LEBLANC; ZUBEK, 2004; SALEN; ZIMMERMAN, 2012; SCHELL, 2011; KAPP; BOLLER, 2018;). De modo resumido, as mecânicas correspondem ao conjunto de ações, affordances e mecanismos de controle disponibilizados ao jogador, podendo incluir ainda outras "engrenagens" essenciais ao funcionamento de um game, como níveis, recursos e configurações de jogo. No xadrez, as mecânicas abarcam a movimentação de peças em turnos, o tipo de movimentação de cada peça no tabuleiro, a captura de peças do adversário, além da possibilidade de encerrar o jogo por meio do xeque-mate. Já em Super Mario World, as mecânicas de jogo envolvem tanto comandos básicos do personagem principal (andar, correr, saltar, rodopiar), quanto elementos do gameplay que não estão sob o controle do jogador, como os power ups que oferecem habilidades ao herói (cogumelos, flores, penas e estrelas), além dos obstáculos específicos de cada fase (bolas de lava, blocos de concreto, balas de canhão). As mecânicas têm servido de base para processos de definição e classificação de games a partir de seus traços formais, tais como gênero (ação em primeira pessoa, sidescroller, beat'em up, luta, hack'n'slash), condições de vitória (superar o adversário, alcançar a linha de chegada), número de jogadores (um jogador, dois jogadores em modo cooperativo, dois jogadores em modo competitivo, multijogador), entre outros.

Outra função das mecânicas é possibilitar o surgimento de dinâmicas de jogo, isto é, instigar no jogador certas condutas e comportamentos em sintonia com os propósitos do game. Um mesmo jogo pode conter diferentes dinâmicas, assim como definir uma hierarquia própria entre elas: enquanto algumas são primárias, isto é, indispensáveis para se alcançar os objetivos do jogo e vencê-lo, outras assumem função secundária, restringindo-se ao nível da estratégia e ao cumprimento de tarefas não obrigatórias. No xadrez, enquanto a dinâmica primária consiste em superar um adversário numa batalha por turnos, as secundárias envolvem a conquista de território e a gestão inteligente de recursos - nesse caso, as peças sob o controle de cada participante. Em suma, enquanto as mecânicas estão inscritas e frequentemente programadas no sistema formal do jogo, as dinâmicas emergem da interação entre os jogadores e as mecânicas materializadas no gameplay. 
O leque de dinâmicas existentes é quase tão extenso quanto o próprio conjunto de ações potencialmente realizáveis pelos seres humanos. Ainda assim, não é difícil encontrar autores que, mesmo diante da impossibilidade de formular um mapa completo, empenham-se na tarefa de inventariá-las, como é o exemplo de Brathewaite e Schreiber (2009), que elencam os padrões vistos no quadro 2:

Quadro 2 - Dinâmicas nucleares

\begin{tabular}{|l|l|}
\hline \multicolumn{1}{|c|}{ Dinâmica Dinâmicas nucleares } \\
\hline $\begin{array}{l}\text { Conquista } \\
\text { território }\end{array}$ & Exemplos de jogos \\
\hline Adivinhação & War / Starcraft \\
\hline Raciocínio espacial & Forca/Imagem \& Ação / Campo minado \\
\hline Sobrevivência & Don't Starve / Day Z/Ark \\
\hline Construção & Simcity /Civilization \\
\hline Destruição & Angry Birds / Plague Inc. \\
\hline Coleção & Damas /Magic /Hearthstone \\
\hline Persiga e escape & Pacman / Friday 13th:The Game / Pique-bandeira \\
\hline Negociação/troca & Pokémon /Animal Crossing /Catan \\
\hline $\begin{array}{l}\text { Corrida até a linha de } \\
\text { chegada }\end{array}$ & Jogo da Vida / Super Mario World /Gran Turismo \\
\hline
\end{tabular}

Fonte: Brathewaite e Schreiber (2009, p. 6-8).

As mecânicas e dinâmicas são como "átomos" e "moléculas" das experiências de jogo e estão no cerne de inúmeras teorias dedicadas aos videogames. No âmbito do design, não é difícil perceber a existência de aportes sustentados nessas categorias. Em geral, cada uma dessas formulações apresenta visões próprias sobre o que os jogos “são", além de técnicas e orientações para o desenvolvimento de games capazes de atingir os objetivos de seus criadores e agradar os jogadores. Além da interação lúdica significativa, outras propostas dignas de atenção circulam nesse campo, a exemplo da tétrade elementar (SCHELL, 2011), da teoria da diversão (KOSTER, 2004), da teoria do fluxo (CSIKSZENTMIHALYI, 2000) ou, ainda, do MDA Framework (HUNICKE; LEBLANC; ZUBEK, 2004). Em alguma medida, o game design estabelece com os jogos digitais uma relação similar àquela que a ortografia e a gramática estabelecem com a linguagem verbal: são fontes de regras e prescrições que fornecem as bases para suas respectivas “normas cultas". No caso dos jogos, esses imperativos se traduzem na forma de princípios como a usabilidade, o balanceamento e a eficácia do gameplay em termos de imersão e engajamento (“diversão"). 
Os conhecimentos construídos durante a instrução explícita assumem valor estratégico no âmbito do enquadramento crítico, etapa em que os videogames se deslocam da função de objeto de teorização, transformando-se em alvo de observação, análise e avaliação sistemática. Nesse contexto, o uso de conceitos do design de games oferece ao jogador ferramentas com as quais ele pode promover uma "engenharia reversa" do gameplay, tornando-se apto a decompor a totalidade da experiência de jogo, identificar seus componentes fundamentais e traçar as correlações existentes entre cada um eles. Todavia, em virtude de sua natureza interativa, não linear e multissemiótica, os textos dos videogames são polissêmicos e passíveis de observação por diferentes lentes e ângulos. Levando em conta os limites deste trabalho, serão pontuados aqui apenas dois exemplos de abordagens compatíveis com os processos de conhecimento em destaque no enquadramento critico: a análise formal e a análise crítica.

A primeira remete a uma prática bastante popular na área das humanidades. Presente na crítica de arte, na arqueologia, na literatura e no cinema, a análise formal pode ser definida como o processo investigativo em que um artefato, seus elementos constitutivos e as relações entre estes são submetidos a uma descrição minuciosa. Essa pormenorização costuma não incluir aspectos subjetivos e contextuais do objeto examinado, ainda que a análise formal não impeça que essas variáveis sejam observadas num contexto de comparação com outros artefatos. Sob a ótica dos multiletramentos, trata-se de compreender os textos dos games em nível representacional (a que se referem os significados de um jogo) e estrutural (como estão organizados os significados de um jogo).

Lankoski e Björk (2015) explicam que, no âmbito dos jogos, a análise formal é um método cujos resultados frequentemente são utilizados subsidiar outras análises mais profundas. Como mencionado, essa perspectiva exige que os jogos e seu gameplay sejam estudados de modo dissociado de seus fatores circunstanciais. Ao mesmo tempo, os autores esclarecem que os games representam não só um artefato - um “objeto" -, mas também uma atividade - um "fazer" inseparável do artefato. Não obstante, essa distinção parece menos relevante na medida em que ambas as dimensões (artefato e atividade) se confundem ao serem submetidas à observação prática. Além de livros de regras, manuais e guias oficiais, a análise formal recorre aos relatos dos jogadores para 
compreender o gameplay, precavendo-se para não confundir depoimentos sobre experiências subjetivas com as descrições do gameplay em si, as quais devem resultar da triangulação de todas as informações examinadas. Sendo assim, a realização de uma análise formal deve conciliar o ato de jogar um jogo (a atividade) com a subsequente elaboração de uma síntese geral do objeto (o artefato).

Como explicam os autores,

[...] as dinâmicas de jogo são mais facilmente compreendidas no gameplay real, então a maioria das análises o levam em conta, seja mediante pesquisadores jogando, sejam por intermédio da observação de outros jogadores jogando o game. Este jogar pode tomar a forma de um gameplay regular, mas também pode incluir experimentos específicos para compreender ou explorar subpartes de um jogo. Certamente o uso de trapaças, hacks e similares pode ser incentivado devido à sua possibilidade de permitir explorações mais eficientes ou oferecer mais transparência ao sistema do jogo. Independentemente de como o jogo é observado, a sua compreensão deve, entretanto, estar dissociada das circunstâncias de jogo. (LANKOSKI; BJÖRK, 2015, p. 23-24, tradução nossa)

Um dos elementos essenciais para a realização de uma análise formal é a posse de um vocabulário capaz de descrever clara e precisamente o gameplay. Para Lankoski e Björk (2015), a busca por repertórios de palavras suficientemente extensos e eloquentes para serem aplicados a todos os tipos existentes de games é um grande desafio. Por outro lado, além de uma maior dificuldade em sua assimilação, vocabulários enciclopédicos oferecem obstáculos no desenvolvimento de uma visão abrangente acerca dos jogos. A adoção de um léxico excessivamente extenso e pormenorizado está propensa a gerar uma alta quantidade de trabalho supérfluo, uma vez que nem todos os procedimentos e categorias à disposição do pesquisador serão úteis ao tipo de análise empreendida por ele. Desse modo, as principais abordagens da análise formal do gameplay estão inclinadas a utilizar vocabulários minimalistas, pois assim são capazes de reduzir os riscos de incompatibilidade certos tipos de jogo e aumentar sua flexibilidade a diferentes tipos de investigação.

Seguindo nessa linha de raciocínio, Lankoski e Björk (2015) estabelecem um modelo de análise focado naquilo que denominam de "primitivos" (primitives): os tipos básicos de "tijolos" a partir dos quais são construídas as experiências de jogo. Cada 
modalidade de primitivo pode existir em instâncias diferentes e possuir valores individuais, além de outras características capazes de definir o estado do jogo ${ }^{6}$ (game state). Este, por sua vez, não é em si um primitivo, mas apenas um momento do gameplay: num jogo de xadrez, o estado do jogo pode ser expresso pela posição de cada peça no tabuleiro em um turno específico.

Os primitivos estão divididos em três grandes grupos: 1) componentes; 2) ações; e 3) objetivos. O primeiro diz respeito às entidades que podem ser manipuladas pelo jogador ou pelo sistema do jogo, assumindo valores e funções variadas, como delimitar o espaço do jogo. De um lado, os componentes podem conter dentro si outros componentes e variáveis, como um personagem controlado pelo jogador possui variáveis como número de vidas e quantidade de munição. Em outro viés, essas variáveis podem não estar associadas a nenhum componente sob o controle de quem joga, como a contagem regressiva para conclusão de uma fase. Já o segundo tipo de primitivo, as ações, dividem-se em três tipos distintos: a) do jogador - os atos realizados pelo player por meio dos componentes diretamente controlados por ele, ou ainda indiretamente, mediante comandos dados por ele ao sistema, como ocorre em games de simulação (The Sims, Sim City) e tower defense (Plants vs Zombies); b) dos componentes - podem ser estabelecidas mediante a identificação da agência e representação de entidades autônomas, como os zombies de Plants vs Zombies que invadem o jardim do jogador, ou os goombas de Super Mario World que perseguem o herói no intuito de eliminá-lo; e c) do sistema - ações que não são percebidas como originárias do jogador ou de um componente específico, mas que podem afetá-los diretamente, como o desaparecimento de uma linha completa em Tetris ou a definição da próxima peça disponibilizada ao jogador. Por fim, os objetivos correspondem às descrições das condições gerais do estado do jogo que possuem importância inegociável para o gameplay. Em outras palavras, correspondem àquilo pelo que os jogadores precisam se esforçar enquanto

\footnotetext{
6 “Emprestando o termo da ciência da computação, as regras de um jogo fornecem uma máquina de estado. De maneira sucinta, uma máquina de estado é aquela que tem um estado inicial, aceita uma quantidade específica de eventos de entrada usando uma função de transição de estado (isto é, regras) e produz saídas específicas usando uma função de saída. Em sentido literal, o jogo é uma máquina de estado: um jogo é uma máquina que pode estar em diferentes estados, ele responde diferentemente à mesma entrada em momentos diferentes, ele contém funções de entrada e saída e definições de que estado e que entrada levarão ao estado seguinte (Por exemplo, a peça se move de E2 para E4, mas não para E5; se você for acertado pelo lança-foguete, você perde energia; se sua base for tomada, você morre). Quando você joga, está interagindo com a máquina de estado que é o jogo." (JUUL, 2019, p. 65, grifo do autor).
} 
jogam. Geralmente, os objetivos estão ligados uns aos outros por uma estrutura hierárquica, podendo assumir a forma de finalidades de curto e longo prazo, bem como de metas obrigatórias (missões principais) e facultativas (missões secundárias e side quests).

Do ponto de vista prático, a análise crítica dos games apresenta diferenças relevantes em relação à análise formal. Enquanto esta detém uma feição notadamente descritiva e almeja um olhar apartado do contexto e das impressões pessoais do jogador, aquela assume um caráter avaliativo e, como tal, promove juízos de valor, mérito e qualidade. De um lado, a análise formal se concentra na compreensão do gameplay nos já referidos níveis representacional e estrutural; de outro, a análise crítica avança para as questões ligadas ao domínio social (como os significados de um jogo conectam os jogadores), à intertextualidade (como os signos de um jogo se encaixam num contexto mais amplo de significados) e ao domínio ideológico (a que interesses os significados de um jogo estão inclinados a servir).

Por conta de sua natureza complexa, os games estão abertos a múltiplas estratégias de observação, dentre as quais se sobressaem aquelas que incidem diretamente sobre suas narrativas, mecânicas, dinâmicas, e até mesmo sobre os códigos presentes no nível da programação. Ainda assim, é importante admitir que a "crítica" aplicada a qualquer modalidade textual, a exemplo dos próprios jogos, deve estar ciente da sua impossibilidade de atingir qualquer estado de onisciência, uma vez que, para garantir sua viabilidade e exequibilidade, esse esforço depende da definição de recortes e parâmetros de apreciação restritos, configurando-se, portanto, como um modo de decodificação inerentemente redutor.

Dito isso, é possível identificar potenciais contribuições para a análise crítica dos games. Um dos exemplos vem de Zagal (2008), que propõe um framework para o letramento em jogos digitais no qual são apresentados eixos de observação capazes de contribuir com o amadurecimento de uma compreensão expandida sobre os games. Enquanto a análise formal se exime de abordar elementos circunstanciais, o modelo em questão segue no caminho contrário, priorizando a descrição minuciosa dos fatores contextuais mais relevantes na configuração de uma experiência de jogo. A partir deles 
são definidas as relações de um game com outros meios, com outros games e com seu contexto cultural mais amplo (Quadro 3).

Quadro 3-Situando os games como artefatos culturais

\begin{tabular}{|c|c|}
\hline \multicolumn{2}{|c|}{ Games como artefatos culturais } \\
\hline Situação & Exemplo \\
\hline $\begin{array}{l}\text { Games como parte de uma ecologia } \\
\text { narrativa transmidiática }\end{array}$ & $\begin{array}{l}\text { Alguns jogos da série Star Wars estendem o universo e } \\
\text { as estórias para além do que exibem os filmes }\end{array}$ \\
\hline $\begin{array}{l}\text { Games como remediação de } \\
\text { artefatos culturais de outras mídias }\end{array}$ & $\begin{array}{l}\text { Alguns jogos são adaptações de histórias em } \\
\text { quadrinhos, livros e filmes }\end{array}$ \\
\hline $\begin{array}{l}\text { Games compartilhando qualidades } \\
\text { temáticas e estéticas de um gênero } \\
\text { midiático mais amplo }\end{array}$ & $\begin{array}{l}\text { Deus Ex (2000) compartilha visões sombrias e distópicas } \\
\text { do gênero de ficção científica chamado ciberpunk }\end{array}$ \\
\hline $\begin{array}{l}\text { Games como parte de um } \\
\text { movimento artístico mais amplo }\end{array}$ & $\begin{array}{l}\text { O movimento cultural surrealismo usa jogos para } \\
\text { fornecer inspiração e um método de investigação, What } \\
\text { Remains of Edith Finch (2017) e Machinarium (2009) }\end{array}$ \\
\hline $\begin{array}{lcr}\text { Games } & \text { partilhando } & \text { práticas } \\
\text { discursivas } & \text { de } & \text { subculturas } \\
\text { específicas } & & \\
\end{array}$ & $\begin{array}{l}\text { Parappa The Rapper (1996) propõe uma imersão na } \\
\text { cultura do hip-hop }\end{array}$ \\
\hline $\begin{array}{l}\text { Games promovendo valores e } \\
\text { pontos de vistas de determinadas } \\
\text { culturas e sociedades }\end{array}$ & $\begin{array}{l}\text { Jogos de guerra como Medal of Honores (1999) } \\
\text { costumam retratar a } 2^{\text {a }} \text { Guerra Mundial exclusivamente } \\
\text { pela ótica das forças aliadas }\end{array}$ \\
\hline
\end{tabular}

Fonte: Zagal (2008).

Atualmente, esse tipo de análise tem se dividido em duas modalidades distintas, a saber: a) a crítica acadêmica; e b) a crítica jornalística. A primeira é impulsionada pelo nítido protagonismo de disciplinas das ciências humanas e sociais, como a Sociologia, a Antropologia, a Filosofia, a História, a Psicologia, as Artes, a Comunicação e as Ciências da Educação. Nesse domínio, boa parte das análises realizadas se concentra no viés discursivo das representações contidas nos games, problematizando-as a partir de categorias-chave ligadas a gênero, raça, etnia e classe (GRAY, 2014; RUBERG; SHAW, 2017; WOODCOCK, 2019). Trata-se de revelar as nuances políticas dos jogos e evidenciar sua função ideológica por intermédio de posicionamentos implícitos nos significados que veiculam por intermédio de mecânicas, dinâmicas e estórias, revelando seus impactos em disputas e relações de poder do passado e do presente.

Distanciando-se da vertente acadêmica, a crítica jornalística dirigida aos games demonstra elevada popularidade entre gamers e simpatizantes. Na forma de reviews em sites especializados como IGN e de videoanálises em canais do YouTube, esses relatos estão intimamente ligados ao campo do jornalismo cultural, cumprindo um papel semelhante ao da crítica fílmica, literária e televisiva. Seus objetivos estão menos 
alinhados à rígida e metódica lógica científica e mais próximos a um tipo de descrição que combina fruição estética e controle de qualidade. A crítica jornalística dedicada aos games pende entre a apreciação do mérito artístico e a avaliação de relações de custobenefício de cada jogo, aqui entendido como produto comercial (CRUZ JUNIOR, 2014). Ao mesmo tempo em que ajuda a formar o "gosto" do jogador ao oferecer-lhe informações sobre os avanços técnicos e criativos de um título em relação a um gênero ou a uma franquia, também atua como uma espécie de guia de compras que visa influenciar a decisão de adquirir (ou não) um jogo.

Em alguma medida, tanto a abordagem acadêmica quanto a jornalística apresentam princípios importantes para a análise crítica dos games. Mesmo sendo distintas ou até opostas em aspectos particulares, é vantajoso buscar propostas que se esforcem em unir e conciliar o melhor de ambas as perspectivas. Diante dessa demanda, o trabalho de Fernandez-Vara (2015) adquire destaque, ao fornecer um dos modelos analíticos mais robustos e ao mesmo tempo acessíveis a serviço da compreensão sistemática dos games. Partindo do diálogo com o campo da análise textual, a autora organiza sua proposta em três áreas de observação distintas: 1) contexto - abrange as circunstâncias em que o jogo é/foi jogado e produzido, bem como os outros textos e as comunidades com os quais ele se relaciona; 2) visão geral do jogo - foca as características básicas que distinguem um jogo dos demais e como ele tem sido lido, apropriado e modificado por diferentes públicos; e 3) aspectos formais - estudo dos elementos estruturais presentes na construção do texto, assim como das partes que o constituem.

O primeiro domínio (o contexto) abrange elementos como a equipe de produção/desenvolvimento, o gênero do jogo, o público, os contextos tecnológico, sóciohistórico e econômico e as relações com outras mídias. Já a visão geral do jogo inclui informações sobre o número de jogadores, as regras e os objetivos do(s modos de) jogo, as mecânicas, os espaços de jogo, o mundo ficcional, a estória, a experiência (pessoal) de gameplay e as comunidades de jogadores. Por fim, os aspectos formais incidem sobre as regras do mundo do jogo, as regras diegéticas e extradiegéticas, as relações entre as regras e o mundo ficcional, os valores e a retórica procedural, os conteúdos procedurais e codificados, as dinâmicas, os esquemas de controle e periféricos, os níveis de dificuldade e balanceamento, a representação (design visual, de áudio e música), os níveis e o level design, e as trapaças/hacks/mods/bugs. 
Diferentemente da proposta de Lankoski e Björk (2015), o modelo de FernandezVara (2015) destaca a relevância das inter-relações entre fatores contextuais e elementos formais no processo de compreensão de um jogo. O modo como um único componente estrutural de um game é interpretado pode variar, por exemplo, de acordo com o histórico da franquia ou do gênero ao qual ele pertence. Ou seja, esse elemento está sujeito a ser avaliado de formas distintas, podendo ora ser aclamado como "revolucionário", ora receber o rótulo "mais do mesmo". Em 2013, a franquia Tomb Raider sofreu um reboot que alterou não apenas as mecânicas de jogo, mas também o modo como sua icônica personagem principal, Lara Croft, vinha sendo representada visual e narrativamente. Ao longo de sua existência, a série sofreu críticas cada vez mais severas pelo caráter excessivamente sexualizado da protagonista, que foi considerada uma figura desenhada para satisfazer desejos e fantasias do imaginário masculino? Consolidada em Rise of Tomb Raider (2015), a mudança radical no perfil de Lara emergiu de um contexto sócio-histórico de contestação de formas estereotípicas de representação feminina, bem como de um contexto econômico em que as mulheres se consolidam como fração significativa do público consumidor de videogames.

Por fim, a prática transformada é uma ocasião oportuna para a culminância dos conhecimentos construídos nas fases da prática situada, da instrução explícita e do enquadramento crítico. Em linhas gerais, esse momento consiste em provocar os educandos a realizar uma intervenção no mundo real por intermédio dos games. As interpretações mais comuns dessa demanda apontam para práticas ligadas à modificação e ao desenvolvimento de jogos digitais. Atualmente, há uma oferta crescente de softwares criados especificamente com essa finalidade, muitos, inclusive, são gratuitos, livres e de código aberto. Nesse conjunto figuram desde aplicações mais simples e amigáveis a crianças, como o Scratch ${ }^{8}$, até motores avançados como Godot ${ }^{9}$, utilizados por empresas e profissionais do ramo, passando por ferramentas intermediárias como o Gdevelop ${ }^{10}$. Cada um desses recursos conta com o apoio e suporte de sua respectiva comunidade de usuários, nas quais, por sua vez, circulam informações, dicas e tutoriais,

\footnotetext{
${ }^{7}$ Mais detalhes em: https://meiobit.com/330748/roteirista-diz-que-sexualizacao-da-lara-croft-ficou-no-passado/. Acesso em: 14 de janeiro de 2020.

${ }^{8}$ https://scratch.mit.edu/. Acesso em: 14 de janeiro de 2020.

${ }^{9}$ https://godotengine.org/. Acesso em: 14 de janeiro de 2020.

${ }^{10} \mathrm{https}: / / g d e v e l o p-a p p . c o m /$. Acesso em: 14 de janeiro de 2020.
} 
além de projetos individuais e coletivos que são produzidos e socializados em regime de intensa cooperação.

$\mathrm{Na}$ condição de processo cognitivo primário da prática transformada, a aplicação envolve a imersão e o enfrentamento de situações que reproduzem a complexidade do mundo real, no intuito de testar e validar conhecimentos e competências de multiletramento construídas pelo educando. Nesse sentido, a meta de "aplicar apropriadamente" pode ser traduzida em atividades de planejamento e produção de games, tanto a partir de diretrizes formais, como as que são estabelecidas pelo game design, quanto com base em orientações mais abrangentes, como a elaboração de representações alternativas de práticas, cenários e personagens normalmente retratados de modo simplista, caricatural ou mesmo pejorativo nos games mainstream. Trata-se, portanto, de estimular o "uso adequado" da linguagem dos jogos para a elaboração de textos lúdicos capazes de produzir discursos e contradiscursos interativos dotados de eficácia semântica e potencial recreativo.

Além de produzir seus próprios jogos, é conveniente que os educandos assumam parte da responsabilidade na análise e avaliação do trabalho feito pelos pares. Para isso, podem adotar a condição de beta testers que jogam os jogos produzidos durante as atividades, avaliando-os de acordo com parâmetros de adequação predefinidos. Outra possibilidade é a transposição de práticas populares nas indústrias de jogos para as situações didáticas visando maximizar o engajamento dos educandos envolvidos. Um dos exemplos são as game jams: eventos que reúnem desenvolvedores para uma competição envolvendo à criação de jogos num curto período de tempo. Já existem, inclusive, guias e manuais que detalham o processo de implementação de jams como metodologia de ensino aplicável a todo tipo de público e contexto educacional. É justamente o caso de iniciativas como a de Cornish et al. (2017) que, partindo de projetos desenvolvidos em âmbito escolar, prescrevem estratégias e atividades que além de auxiliarem na organização de uma game jam, podem direcioná-la a temáticas munidas de relevância social, como o aquecimento global, a imigração e as histórias locais.

Finalmente, a aplicação criativa representa o momento de livre expressão e experimentação em que os jogos são utilizados como uma maneira de materializar interesses, vivências e aspirações individuais. O objetivo principal é abastecer o mundo com formas de gameplay renovadas que permitam aos jogadores não apenas acessar 
novas sensações e tipos outros de diversão, mas também vislumbrar modos de vida ainda não experimentados. Nesse caso, a quebra de "normas cultas" impostas por sistemas explicativos tradicionais, disciplinas acadêmicas e teorias especializadas, a exemplo do game design, pode não ser equivalente a uma falha técnica passível de correção, e sim a um gesto deliberado de desobediência artística com o objetivo desestabilizar padrões estéticos e de entendimento.

Após descritas as relações entre os jogos digitais e a pedagogia dos multiletramentos, apresento uma breve síntese contendo as principais ações de aprendizagem descritas até então (Quadro 4):

Quadro 4 - A pedagogia dos multiletramentos aplicada aos games

\begin{tabular}{|c|c|c|}
\hline \multicolumn{3}{|c|}{ A pedagogia dos multiletramentos aplicada aos jogos digitais } \\
\hline $\begin{array}{l}\text { Orientações } \\
\text { pedagógicas }\end{array}$ & $\begin{array}{l}\text { Processos de } \\
\text { conhecimento }\end{array}$ & Ações de aprendizagem \\
\hline \multirow[t]{2}{*}{ Prática situada } & $\begin{array}{l}\text { Experienciar... } \\
\text { o familiar }\end{array}$ & $\begin{array}{l}\text { - Identificar e vivenciar os jogos de maior presença em } \\
\text { seu cotidiano } \\
\text { - Estabelecer relações de colaboração com os pares, } \\
\text { visando promover o intercâmbio de informações e } \\
\text { habilidades entre os indivíduos com maior e menor } \\
\text { bagagem prática no âmbito dos videogames }\end{array}$ \\
\hline & $\begin{array}{l}\text { Experienciar... } \\
\text { o novo }\end{array}$ & $\begin{array}{l}\text { - Conhecer títulos, gêneros e estilos de jogo distantes de } \\
\text { sua realidade imediata } \\
\text { - Socializar relatos sobre as vivências de jogo, visando } \\
\text { mapear aspectos significativos da atividade }\end{array}$ \\
\hline \multirow[b]{2}{*}{ Instrução explícita } & $\begin{array}{l}\text { Conceitualizar... } \\
\text { nomeando }\end{array}$ & $\begin{array}{l}\text { - Pesquisar termos recorrentes no vocabulário de } \\
\text { desenvolvedores e jogadores de videogame } \\
\text { - Assimilar e dominar um léxico que auxilie no processo } \\
\text { de descrição e classificação de diferentes jogos digitais }\end{array}$ \\
\hline & $\begin{array}{l}\text { Conceitualizar... } \\
\text { teorizando }\end{array}$ & $\begin{array}{l}\text { - Estudar categorias e ferramentas teóricas que auxiliem } \\
\text { na compreensão da natureza e do propósito dos games } \\
\text { - Investigar, a partir do design de jogos, os diferentes } \\
\text { modos como os videogames produzem o engajamento } \\
\text { e a diversão } \\
\text { - Reconhecer de que maneira essas ideias se } \\
\text { materializam nas experiências de jogo }\end{array}$ \\
\hline \multirow[t]{2}{*}{$\begin{array}{c}\text { Enquadramento } \\
\text { crítico }\end{array}$} & $\begin{array}{l}\text { Analisar... } \\
\text { funcionalmente }\end{array}$ & $\begin{array}{l}\text { - Compreender os jogos e o gameplay a partir de suas } \\
\text { unidades estruturais e representacionais primárias } \\
\text { (componentes, ações e objetivos) } \\
\text { - Reconhecer e associar mecânicas e dinâmicas de jogo } \\
\text { de diferentes naturezas } \\
\text { - Exercitar a consciência de si e dos elementos formais } \\
\text { do jogo durante o gameplay, desenvolvendo o "olhar de } \\
\text { designer" em relação à experiência }\end{array}$ \\
\hline & $\begin{array}{l}\text { Analisar... } \\
\text { criticamente }\end{array}$ & $\begin{array}{l}\text { - Refletir sobre o videogame como artefato cultural, } \\
\text { entendendo suas conexões com outros artefatos, } \\
\text { práticas e grupos socioculturais } \\
\text { - Evidenciar as relações entre elementos formais e } \\
\text { contextuais dos jogos digitais }\end{array}$ \\
\hline
\end{tabular}




\begin{tabular}{|c|c|c|}
\hline & & $\begin{array}{l}\text { - Investigar as problemáticas e limitações presentes nos } \\
\text { significados e nas representações dominantes no } \\
\text { âmbito dos videogames } \\
\text { - Elaborar paratextos (reviews, videoanálises e } \\
\text { podcasts) que expressem avaliações individuais e/ou } \\
\text { coletivas de jogos distintos }\end{array}$ \\
\hline \multirow{2}{*}{$\begin{array}{c}\text { Prática } \\
\text { transformada }\end{array}$} & $\begin{array}{l}\text { Aplicar... } \\
\text { apropriadamente }\end{array}$ & $\begin{array}{l}\text { - Utilizar aplicativos, softwares e engines para criação e } \\
\text { modificação de jogos digitais (Scratch, Godot, Gdevelop) } \\
\text { - Planejar e desenvolver games a partir de diretrizes } \\
\text { técnicas e temáticas predefinidas } \\
\text { - Construir e participar de comunidades de prática e } \\
\text { aprendizagem voltadas à realização de projetos } \\
\text { colaborativos }\end{array}$ \\
\hline & $\begin{array}{l}\text { Aplicar... } \\
\text { criativamente }\end{array}$ & $\begin{array}{l}\text { - Apropriar-se dos jogos digitais como linguagem, } \\
\text { empregando-os como recurso a serviço da } \\
\text { autoexpressão } \\
\text { - Formular propostas de intervenção no mundo real a } \\
\text { partir de experiências de jogo criadas individual e } \\
\text { coletivamente }\end{array}$ \\
\hline
\end{tabular}

Fonte: elaborado pelo autor.

Com base nessas observações, é possível estabelecer aproximações entre a pedagogia dos multiletramentos e os jogos digitais. Por resultarem do esforço de diálogo entre fenômenos dinâmicos e, como tais, complexos, é forçoso admitir que as ações de aprendizagem descritas não representam um modelo fechado e tampouco definitivo. Ainda que possam auxiliar na construção de projetos de intervenção pedagógica, essas indicações possuem um caráter notadamente introdutório e ilustrativo, não devendo ser confundidas como uma tentativa de encerramento do debate.

\section{Considerações finais}

Este trabalho teve como objetivo refletir sobre os jogos digitais no contexto da perspectiva dos multiletramentos, no intuito de reunir subsídios para a formulação de propostas de ensino. A partir de um levantamento bibliográfico, foram apresentadas características gerais da pedagogia dos multiletramentos, entendida como projeto que busca superar a rigidez da alfabetização tradicional, apoiando-se na defesa da multimodalidade da linguagem e inspirando-se no espírito criativo e inovador do design. Ademais, também foram apresentadas características gerais dos jogos digitais, levando em consideração sua natureza lúdica e expressiva. 
No diálogo com essa abordagem, o "como" dos multiletramentos evidenciou a fecundidade de suas orientações pedagógicas, que são organizadas em categorias-chave como a prática situada, a instrução explícita, o enquadramento crítico e a prática transformada. Cada uma delas demonstra potencial para incorporar um sem-número de atividades e práticas socioculturais associadas aos games, bem como maneiras de vivenciá-los, conceituá-los, analisá-los e aplicá-los.

Finalmente, vale esclarecer que não foi objetivo deste trabalho fornecer uma visão conclusiva de todas as contribuições teóricas e metodológicas advindas do campo de conhecimento dos jogos digitais. Distante de oferecer uma resposta final, o interesse primário foi sinalizar a existência de aportes e discussões em andamento, cujo potencial explicativo e formativo tem sido, em alguma medida, subutilizado. Nesse sentido, esperase que o presente artigo possa impulsionar ações pedagógicas concretas em contextos educativos variados, favorecendo reflexões futuras que auxiliem na avaliação e no aperfeiçoamento da sistematização aqui apresentada, bem como na formulação de novos e mais complexos modelos capazes de inspirar professores e demais agentes educativos interessados em compreender e se apropriar dos jogos digitais como conteúdo de ensino.

\section{Referências}

BRATHEWAITE, Brenda; SCHREIBER, IAN. Challenges for game designers: non-digital exercises for videogame designers. Boston: Cengage Learning, 2009.

COPE, Bill; KALANTZIS, Mary. A grammar of multimodality. The International Journal of Learning, Melbourne, v. 16, n. 2, 2009a. Disponível em: http://ijb.cgpublisher.com/product/pub.30/prod.2057. Acesso em: 7 abr. 2013.

COPE, Bill; KALANTZIS, Mary. “Multiliteracies”: new literacies, new learning. Pedagogies: An International Journal, London, n. 913479273, 2009b. Disponível em: http://www.tandfonline.com/doi/abs/10.1080/15544800903076044. Acesso em: 7 abr. 2013.

COPE, Bill; KALANTZIS, Mary. New media, new learning. In: COLE, Darren R.; PULLEN, David L. (org.). Multiliteracies in motion: current theory and practice. London: Routledge, 2009c. p. 85-104. Disponível em:

http://newlearningonline.com/multiliteracies/files/2009/03/colenewmedianewlearningcha pter.pdf. Acesso em: 12 mar. 2013. 
CORNISH, Sara et al. The game jam guide. Pittsburgh: ETC Press, 2017.

COSCARELLI, Carla Viana; KERSCH, Dorotea Frank. Prefácio. In: KERSCH, Dorotea Frank; COSCARELLI, Carla Viana; CANI, Josiane Brunetti (orgs.). Multiletramentos e multimodalidade: ações pedagógicas aplicadas à linguagem. Campinas: Pontes Editores, 2016. p. 7-14.

CRUZ JUNIOR, Gilson. Gaming, cultura e ciberespaço: sobre o "mimimi" em torno de Mass Effect 3 e a compreensão "crítica" dos jogos digitais. Licere, Belo Horizonte, v. 17, n. 4, p. 61-84, 2014.

CRUZ JUNIOR, Gilson. O delinquente em cada um de nós: uma introdução à pedagogia do "mau exemplo" nos videogames. Curitiba: Editora CRV, 2017.

CSIKSZENTMIHALYI, Mihalyi. Fluir: una psicologia dela felicidad. Barcelona: Editora Kairós, 2000.

DUDENEY, Gavin; HOCKLY, Nicky; PEGRUM, Mark. Letramentos digitais. São Paulo: Parábola Editorial, 2016.

FERNANDEZ-VARA, Clara. Introduction to game analysis. New York: Routledge, 2015. GRAY, Kishonna. Race, gender and deviance in Xbox Live: theoretical perspectives from the margins. Waltham: Elsevier, 2014.

HUNICKE, Robin; LEBLANC, Marc; ZUBEK, Robert. MDA: a formal approach to game design and game research. In: PROCEEDINGS OF THE CHALLENGES IN GAME AI WORKSHOP; Nineteenth NATIONAL CONFERENCE ON ARTIFICIAL INTELLIGENCE, 19, 2004, San José-California. Anais [... ]. San José-California: Stanford University, 2004.

JUUL, Jesper. A casual revolution: reinventing video games and their players. Massachusetts: MIT Press, 2010.

JUUL, Jesper. Half-real: videogames entre regras reais e mundos ficcionais. São Paulo: Blucher, 2019.

KAPP, Karl; BOLLER, Sharon. Jogar para aprender: tudo o que precisa saber sobre o design de jogos de aprendizagem eficazes. São Paulo: DVS Editora, 2018.

KOSTER, Raph. A theory of fun for game design. Arizona: Paraglyph Press, 2004.

LANKOSKI, Petri; BJORK, Staffan. Formal analysis of gameplay. In: LANKOSKI, Petri; BJORK, Staffan. Game research methods: an overview. Pittsburgh: ETC Press, 2015. p. 2335 .

MARTIN-BARBERO, Jesús. A comunicação na educação. São Paulo: Contexto, 2014. 
MCGONIGAL, Jane. A realidade em jogo: porque os games nos tornam melhores e como eles podem melhorar o mundo. Rio de Janeio: Best Seller, 2012.

NEWMAN, James. Playing with videogames. New York: Routledge, 2008.

ROJO, Roxane. Gêneros discursivos do círculo de Bakhtin e multiletramentos. In: ROJO, Roxane (orgs.). Escol@ conectada: os multiletramentos e as TICs. São Paulo: Parábola, 2013. p. 13-36.

RUBERG, Bonnie; SHAW, Adrienne. Queer game studies. Minneapolis: University of Minnesota Press, 2017.

SALEN, Katie; ZIMMERMAN, Eric. Regras do jogo: fundamentos do design de jogos. São Paulo: Blucher, 2012.

SCHELL, Jesse. A arte do game design: o livro original. Rio de Janeiro: Elsevier, 2011.

TAYLOR, T. L. Raising the stakes: e-sports and the professionalization of computer gaming. Massachusetts: MIT Press, 2012.

ULICSAK, Mary; WILLIAMSON, Ben. Computer games and learning: a futurelab handbook. London: Futurelab, 2010.

WOODCOCK, Jamie. Marx at arcade: consoles, controllers and class struggle. Chicago: Haymarket Books, 2019.

ZAGAL, José. A Framework for games literacy and understanding games. Future Play 2007, Ontário, p. 33-40, 2008. 